\title{
Role of urban plant environment for sustainable protection of an ancient city wall
}

Yonghui $\mathrm{Li}^{\mathrm{a}, \mathrm{b}^{*}}$, Changchang $\mathrm{Xia}^{\mathrm{a}}$, Ruobin $\mathrm{Wu}^{\mathrm{a}}$, Yan $\mathrm{Ma}^{\mathrm{a}}$, Baogang $\mathrm{Mu}^{\mathrm{c}}$

Tianwen Wang ${ }^{\mathrm{d}}$, Evangelos Petropoulos ${ }^{\mathrm{e}}$, Shuichi Hokoi ${ }^{\mathrm{a}}$

a. School of Architecture, Southeast University, 210096 Nanjing, P.R. China

b. Key Laboratory of Urban and Architectural Heritage Conservation of Ministry of Education (Southeast University),

210096 Nanjing, P.R. China

c. School of Civil Engineering, Southeast University, 210096 Nanjing, P.R. China

d. Nanjing City Wall Protection and Management Centre, Nanjing, China

e. School of Engineering, Newcastle University, NE1 7RU, UK

\begin{abstract}
Cultural heritage sites are exposed to urban environmental phenomena and various forms of deterioration that degrade their historical and cultural value. As an important element, plants landscaping can be a potential regulator of the microenvironment mitigating the adverse effect of the local climate to cultural heritage. The influence of evergreen trees on the weathering deterioration of Nanjing City Wall was studied and evaluated through field measurements and numerical modelling. A two-dimensional hygrothermal 'City Wall-plant' model was developed to simulate the shaded and unshaded surfaces. The results showed that compared with the unshaded case, the shaded surface showed smaller temperature fluctuations with an increase in the minimum temperature by $0.5 \sim 0.8^{\circ} \mathrm{C}$, smaller water content fluctuations with a decrease in the standard deviation by $0 \sim 0.04 \mathrm{~m}^{3} / \mathrm{m}^{3}$, and a lower evaporation rate by $8 \sim 18 \%$. This means that the evergreen trees can effectively reduce the risk of deterioration on wall surfaces due to freeze-thaw cycles, efflorescence, and subflorescence. These findings provide with the theoretical basis for the sustainable preservation of sites with cultural heritage.
\end{abstract}

Keywords: Heritage conservation; Plant regulation; Hygrothermal simulation; Risk of deterioration; City wall;

*Corresponding author: Yonghui LI

E-mail addresses: liyonghui@ seu.edu.cn (Y. LI).

Address: \#2 Sipailou, Xuanwu District, 210096 Nanjing City, Jiangsu Province, P.R. China

Phone: (+86) 025-83790530

Fax: (+86) 025-83790530 


\section{Introduction}

3 Cultural heritage is a witness of cultural values,

4 shared by people during a period. Heritage must be

5 preserved in order to be passed down to the future

6 generations [1]. However, cultural heritage such as

7 buildings, structures and archaeological sites, are

8 directly exposed to the natural environment, and are

9 often affected by solar radiation, precipitation,

10 underlying surface and other climate factors [2, 3],

11 facing weathering, man-made destruction, natural

12 disasters and other threats.

13 The microclimate fluctuations at sites of

14 architectural heritage can seriously affect the rate of

15 buildings' degradation and deterioration. The large-

16 scale brick City Wall (Nanjing, China) is a

17 monument of great heritage exposed to the natural

18 environment, which due to the physical properties

19 (high porosity, high water absorption, etc.) of the

20 brick, it is easier to be deteriorated. Jin and Zhang

21 et.al found that phenomena of efflorescence,

22 exfoliation, pelletizing, powdering, and flaking on

23 wall bricks, are often related to the rise of salt-

24 containing capillary water, as well as in differences

25 in the concentration and type of the ions therein [4,

26 5]. Waragai et.al found that the base of sandstone

27 pillars in Angkor Wat temple, having different

28 orientations, were deteriorated to diverse degrees;

29 this was mainly attributed to direct exposure to solar

30 radiation together with rainfall [6]. Erkal et.al also

31 proved that the erosion and degrading strength of

32 building materials is effected by the wind-driven

33 rain [7]. Moreover, D'Ayala et.al investigated the

34 adverse effect of the rain under extreme climate

35 conditions on the preservation of historical

36 buildings [8]. Consecutive freeze-thaw cycles may

37 also lead to the reduction in structural/mechanical

38 strength of porous building materials [9], i.e. stone

39 and bricks, another key factor of architectural

40 heritage deterioration. The degree of the freeze-thaw

41 damage is directly related to the frost temperature

42 and moisture content [10]. Accordingly, Zhou et.al

43 further investigated the influence of climate change

44 on freeze-thaw risk of internally insulated masonry

45 walls [11].

46 Typically, an appropriate, well regulated

47 hygrothermal microclimate will benefit the

48 architectural heritage conservation. Studies have

49 shown that vegetation has the capacity to regulate

50 the microclimate in urban environments.

51 Specifically, trees with giant canopy are able to
52 reduce downward short-wave radiation [19],

53 decelerate the wind speed, cool down the

54 surrounding area through respiration [20], regulate

55 the ambient air temperature and humidity [21, 22].

56 Employment of plantation(s) to mitigate the adverse

57 environmental impact of phenomena to building

58 elements is a very common strategy, 'green' roofs

59 and/or 'green' walls often built to decrease the

60 surface temperature and regulate the internal

61 buildings' environment [23, 24]. Researches trialled

62 different species of trees and showed that their effect

63 on environmental regulation varies per speciation

64 [25]. Fundamental species-based features are, tree

65 arrangement, amount of leaves, Leaf Area Index and

66 other tree crown-related characteristics [26, 27].

67 Furthermore, the potential of vegetation in

68 regulating microclimate has been explored in

69 heritage protection applications. It is well known

70 that vegetation near the archaeological site reduces

71 the risk of thermal shocks and makes the relative

72 humidity optimal for buildings' preservation [28].

73 For example, English ivy has been found to reduce

74 the range and variability of wall-surface

75 microclimates over diurnal, seasonal, and annual

76 timescales [29] as well as to reduce the frequency,

77 duration, and severity of freezing events [30] at

78 historic sites in England. Another study showed that

79 presence of vegetation in close proximity to an

80 ancient temple regulates its ambient environment

81 significantly minimizing the stone loss effect [31].

82 These findings shout of the beneficial character of

83 plantation in the conservation of buildings' heritage.

84 Essentially, the shading of trees may offer a

85 potential solution for the preservation of largescale

86 heritage sites. However, regulation of heat and

87 humidity phenomena at heritage sites, by

88 introducing plants, is a mechanism that remains

89 unexplored. We hypothesize that their presence may

90 promote preservation; however, the mechanism and

91 the exact impact of plantation to the conservation of

92 cultural heritage via tackling weathering and

93 degradation is yet unclear.

94 Nanjing City Wall (N: 3206"; E: $118^{\circ} 79^{\prime \prime}$ ), one

95 of the most important cultural heritages in China,

96 has a long history that can be traced back over 600

97 years. It is an ancient structure of enormous

98 historical and cultural heritage value, among which

99 are inscriptions that contain information of

100 responsible organizations and persons on the bricks

101 [33]. However, Nanjing City Wall has been exposed 
102 to climatic variations for centuries and deteriorated

103 by peeling and cracking which damaged surface 104 inscriptions.

105 This study aims to evaluate the influence of trees 106 around the wall on the weathering deterioration of 107 the Nanjing City Wall was studied and evaluated 108 through field measurements and numerical 109 modelling. The results were used to formulate 110 guidelines for the landscape design around the City 111 Wall, hoping to further promote the rationalization 112 behind sustainable development and management of 113 urban landscape design.

114

\section{Materials and methods}

116 A field parameters' measurement and simulation

117 approach was adopted for this research work.

118 Specifically: field measurements, the influence of

119 trees on the hygrothermal characteristics of the wall

120 surface were preliminarily evaluated. Then, due to

121 limited measurement conditions, simulation was 122 used for the evaluation of the influence of trees on 123 the risks from freeze-thaw and salt crystallization to 124 a masonry wall, the Nanjing City Wall in this study.

\section{$125 \quad 2.1$ Measurements}

126 Nanjing city is located at Eastern China, 127 subjected to the Yangtze River. In year 2019, the

128 temperature fluctuated between $-2.6^{\circ} \mathrm{C}$ and $40^{\circ} \mathrm{C}$ 129 with average temperature of $17^{\circ} \mathrm{C}$; the relative 130 humidity fluctuated between $15.8 \%$ and $100 \%$. The 131 annual average rainfall was $1245 \mathrm{~mm}$ for the last 10 132 years. Jiefang gate is one of the gates located at the 133 northern part of Nanjing City Wall. Two parts (Site 1341 and Site 2) were selected and measured on the 135 west of Jiefang gate from April 2019 (Fig. 1a).

136 There was a $7.5 \mathrm{~m}$ high Osmanthus tree (evergreen) 137 about $3.5 \mathrm{~m}$ away from the south facade of City Wall 138 at Site 1 . The air temperature and relative humidity 139 under the canopy, the surface temperatures and 140 water content of the City Wall were measured. The 141 temperatures were measured at heights of $1.2 \mathrm{~m}, 3.9$ $142 \mathrm{~m}$, and $5.4 \mathrm{~m}$, and the water content were measured 143 at heights of $0.15 \mathrm{~m}, 1.2 \mathrm{~m}$, and $2.1 \mathrm{~m}$ (Fig. 1b). 144 Hereafter, these heights are denoted as $\mathrm{H}_{0.15}, \mathrm{H}_{1.2}$, 145 etc.

146 Site 2 was selected about 14 meters apart from 147 Site 1. On the south side of Site 2, there is a $5 \mathrm{~m}$ 148 high Osmanthus tree about $5 \mathrm{~m}$ away from the City 149 Wall. The tree shades the lower part of the wall 150 surface only for a limited period of the year. The
151 temperature was measured at a height of $3.9 \mathrm{~m}\left(\mathrm{H}_{3.9}\right)$

152 from the ground to represent the temperature on an 153 unshaded surface (Fig. 1c). This point is hereafter 154 regarded as the unshaded point.

155 The surface temperatures at three heights $\left(\mathrm{H}_{1.2}\right.$, $156 \mathrm{H}_{3.9}$, and $\mathrm{H}_{5.4}$ ), and ground surface temperature were 157 measured by T-type thermocouples and recorder 158 (type: GRAPHTEC GL240; origin: Japan; 159 precision: $\pm 0.5{ }^{\circ} \mathrm{C}$; measurement range: $-200{ }^{\circ} \mathrm{C}$ $160400{ }^{\circ} \mathrm{C}$ ) powered by a solar panel. The air 161 temperature and humidity under the canopy were 162 measured by electronic temperature and humidity 163 recorders (type: HOBO MX2301; origin: America; 164 precision: $\pm 0.2{ }^{\circ} \mathrm{C}$ and $\pm 2.5 \%$, respectively; 165 measurement range: $-40{ }^{\circ} \mathrm{C} \sim 70{ }^{\circ} \mathrm{C}$ and $0 \% \sim$ 166 167 $100 \%$, respectively).

The water content was measured by a moisture meter (type: Testo 616; origin: German; precision: $\pm 0.1 \%$; measurement range: $0 \% \sim 20 \%$ ). The water content of the brick over a depth of $5 \mathrm{~cm}$ was measured by this sensor. The 10 horizontally consecutive bricks were measured at three heights $\left(\mathrm{H}_{0.15}, \mathrm{H}_{1.2}\right.$, and $\left.\mathrm{H}_{2.1}\right)$. The average value of 10 bricks was used to represent the water content at each height.

The air temperature and relative humidity under the canopy, and surface temperatures were recorded every 30 minutes from June to December in 2019, and the water content measurements were conducted on every ten days from April to December in 2019.

The meteorological data were recorded by HOBO Station (type: HOBO RX3003; origin: America) located at Southeast University (800 m apart from the monitored site). The monitored weather data included the temperature, relative humidity, rainfall, and horizontal global solar radiation, which were recorded at 5 minutes' intervals. The measurement range of the air temperature, relative humidity, rainfall and solar radiation are $-40 \sim+75^{\circ} \mathrm{C}$ (precision: $\pm 0.21^{\circ} \mathrm{C}$ ), $0 \sim 100 \%$ (precision: $\pm 2.5 \%$ ), $0 \sim 12.7 \mathrm{~cm} / \mathrm{h} \quad$ (precision: $\pm 1 \%$ ), $\quad 0 \sim 1280 \mathrm{~W} / \mathrm{m}^{2}$ (precision: $\pm 10 \mathrm{~W} / \mathrm{m}^{2}$ ), respectively. 


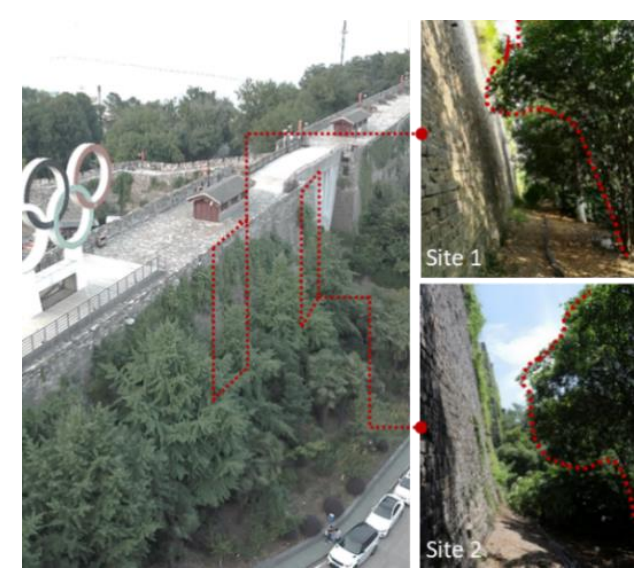

(a)

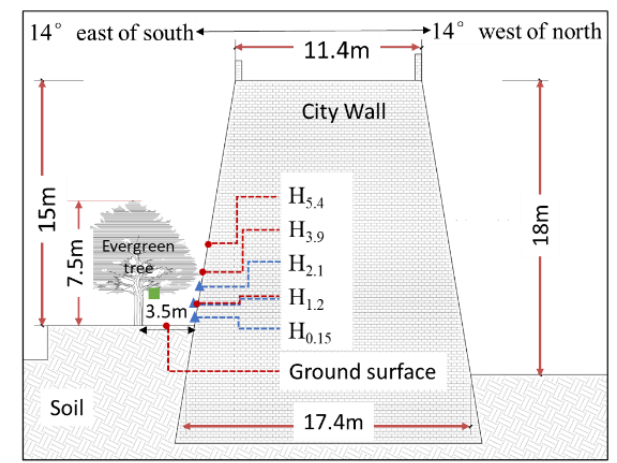

- Surface temperature $(1.2 \mathrm{~m}, 3.9 \mathrm{~m}, 5.4 \mathrm{~m})$

- Temperature /Relative humidity of air under the canopy $\Delta$ Water content $(0.15 \mathrm{~m}, 1.2 \mathrm{~m}, 2.1 \mathrm{~m})$

(b)

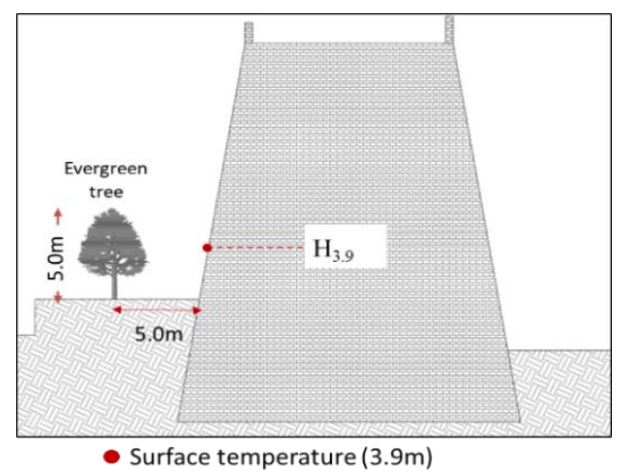

(c)

Fig. 1 Environment monitoring: (a) Photos of monitoring sites; (b) Measure points at Site 1;

(c) Measure points at Site 2

\section{2.2 Simulation model}

\section{2.2.1 City Wall-Plant model}

196 A City Wall-Plant model proposed for this

197 research, presented schematically in Fig. 2. The

198 model contains four elements: the ground, city wall,

199 canopy, and the air space under the canopy. They

200 are all assumed porous materials. The calculation of

201 the energy and water budget quantifies both the flow

202 of heat and moisture that occur in the ground, from the city wall, the canopy, and the air space under the canopy.

Based on the meteorological data, the exchange of heat and moisture at all interfaces (ground/city wall-outdoor air, canopy- outdoor air, and ground/city wall-the air under the canopy) were calculated.

In the plant model, the canopy can reduce the incident solar radiation to the shaded ground and wall surface, and intercept the rainfall that dropped to vertical projection region (the ground and wall).

As a result, the temperature and moisture content of these elements were decided. These parameters interact with each other, thus, they were calculated by solving them simultaneously. Based on the obtained simulated results (temperature and moisture content of the wall surface) we could evaluate the deterioration of the wall, and subsequently the effect of the plant to the wall status.

\subsubsection{City Wall model}

Araoka et al. built a two-dimensional hygrothermal model of Nanjing City Wall, which considered a composite structure consisting of brick and mortar, to examine the influence of rainwater infiltration [32]. As we focused on the influence of vegetation on the hygrothermal state of City Wall, it was simply modeled as a full brick structure. The simultaneous transfer model of heat and water by Matsumoto [34] was adopted in this paper. In this model, the water chemical potential $\mu$ is used to express the moisture state. The relationship between $\mu$, temperature, and relative humidity is given as follows:

Heat balance equation:

$$
\mu=R_{v} T \ln (h)
$$

$$
c \rho \cdot \frac{\partial T}{\partial t}=\nabla\left[\left(\lambda+\lambda_{T g}^{\prime}\right) \nabla \mathrm{T}+r \lambda_{T g}^{\prime} \nabla \mu\right]
$$

Moisture balance equation:

$$
\rho_{w}\left(\frac{\partial \Psi}{\partial \mu}\right)\left(\frac{\partial \mu}{\partial t}\right)=\nabla\left[\lambda_{\mu}^{\prime}(\nabla \mu-g \boldsymbol{n})+\lambda_{T}^{\prime} \nabla T\right]
$$

\subsubsection{Plant model}

Plant models have been extensively studied. Frankenstein et al. [35] proposed low-vegetation (shrubs, crops, grass, etc.) and high-vegetation models (trees and canopy) based on a previous model [36-38]. Low-vegetation models have been studied and applied to analyze the thermal behavior of the green building envelope or the building's energy consumption [39, 40]. 
In our model, trees played the role of reducing

251 solar radiation to and the nocturnal radiation from

252 the wall. Furthermore, the rainwater trapped by trees

253 evaporates and removes heat from the plants. The

254 model was based on the plant model by Kondou [41],

255 and was applied to the shaded ground and walls. The

256 plant model was developed consisting of two nodes:

257 one representing a homogeneous canopy of trees

258 and the another for the air space under the canopy.

259 Fig. 2a-2b shows the thermal and moisture networks

260 of the developed plant model, in which, the thermal

261 resistance, the transmittance coefficient of the

262 canopy to solar radiation and rain were used to

263 characterize the canopy structure of trees. The

264 equations of heat and moisture balance of the plants

265 are shown on Appendix B.

\section{2.3 Calculation method}

267 An explicit control volume method was adopted

268 for the calculations with a time step of 30 seconds.

269 The initial conditions of the calculation were

270 determined by the relevant annual cycle data,

271 carried out in City Wall-Plant model using the

272 weather data monitored by the year 2018 (repeatedly

273 for 10 years). Fig. 2c shows the region of

274 calculations and the boundary conditions. The two-

275 dimensional calculation region $(44.5 \mathrm{~m} \times 34.8 \mathrm{~m})$ is

276 divided into 451 (horizontal) $\times 176$ (vertical) meshes

277 with different mesh size. A third kind of boundary

278 conditions was used at the ground-air and wall-air

279 boundary surfaces. At the bottom of the calculation

280 region $(-15 \mathrm{~m}$ under the ground surface), the

281 boundary conditions refer to the first kind of

282 boundary conditions (temperature is $17^{\circ} \mathrm{C}$ and water

283 chemical potential is $-5 \mathrm{~J} / \mathrm{kg}$ ).

284 The heat and moisture flux on the boundary of

285 the of the unshaded wall/ground surface (Boundary

286 A in Fig. 2c) is expressed as follows:

287 Heat:

288

289

290

$$
\begin{gathered}
\left(\alpha_{o m}+r \alpha_{T}^{\prime}\right)\left(T_{o}-T_{m}\right)+r \alpha_{\mu}^{\prime}\left(\mu_{o}-\mu_{m}\right)+I_{s o l} \cdot A_{m}-\varepsilon_{m} \cdot I_{n o c} \\
=-\left.\left(\lambda+r \lambda_{T g}^{\prime}\right) \frac{\partial T}{\partial n}\right|_{S}-\left.r \lambda_{\mu g}^{\prime} \frac{\partial \mu}{\partial n}\right|_{s}(4)
\end{gathered}
$$$$
\text { Heat: }
$$

Moisture: $P_{r}+\alpha_{\mu}^{\prime}\left(\mu_{o}-\mu_{m}\right)+\alpha_{T}^{\prime}\left(T_{o}-T_{m}\right)$

$$
=-\lambda_{\mu}^{\prime} \cdot\left(\left.\frac{\partial \mu}{\partial \mathrm{n}}\right|_{S}-n_{X} \cdot g\right)-\left.\lambda_{T}^{\prime} \frac{\partial T}{\partial n}\right|_{S}
$$

292 The heat and moisture flux on Boundary B in Fig.

293 2c is expressed as follows:

294 Heat:

295

296
310

\section{Measured and Calculated Results}

\section{3.1 Measured results}

321

322

Moisture: $\gamma^{\prime} \cdot P_{r}+\alpha_{\mu}^{\prime}\left(\mu_{o}-\mu_{m}\right)+\alpha_{T}^{\prime}\left(T_{o}-T_{m}\right)$

$$
=-\lambda_{\mu}^{\prime} \cdot\left(\left.\frac{\partial \mu}{\partial n}\right|_{S}-n_{x} \cdot g\right)-\left.\lambda_{T}^{\prime} \cdot \frac{\partial T}{\partial n}\right|_{S}
$$

The temperature and relative humidity of the air under canopy were calculated by Eq. (B5), (B7), shown in Appendix B, for the calculation needs, one particle indicates the air under canopy. The heat and moisture flux on Boundary C in Fig. 2c is expressed as follows:

Heat:

$$
\begin{array}{r}
\left(\alpha_{a m}+r \alpha_{T}^{\prime}\right)\left(T_{a s}-T_{m}\right)+r \alpha_{\mu}^{\prime}\left(\mu_{a s}-\mu_{m}\right)+\gamma \cdot\left(I_{s o l} \cdot A_{m}-\varepsilon_{m} \cdot I_{n o d}\right) \\
=-\left.\left(\lambda+r \lambda_{T g}^{\prime}\right) \frac{\partial \mathrm{T}}{\partial \mathrm{n}}\right|_{\mathrm{s}}-\left.r \lambda_{\mu g}^{\prime} \frac{\partial \mu}{\partial \mathrm{n}}\right|_{\mathrm{s}}(8)
\end{array}
$$

Moisture: $\gamma^{\prime} \cdot P_{r}+\alpha_{\mu}^{\prime}\left(\mu_{a s}-\mu_{m}\right)+\alpha_{T}^{\prime}\left(T_{a s}-T_{m}\right)$

$$
=-\lambda_{\mu}^{\prime} \cdot\left(\left.\frac{\partial \mu}{\partial n}\right|_{S}-n_{x} \cdot g\right)-\left.\lambda_{T}^{\prime} \frac{\partial \mathrm{T}}{\partial \mathrm{n}}\right|_{\mathrm{S}}
$$

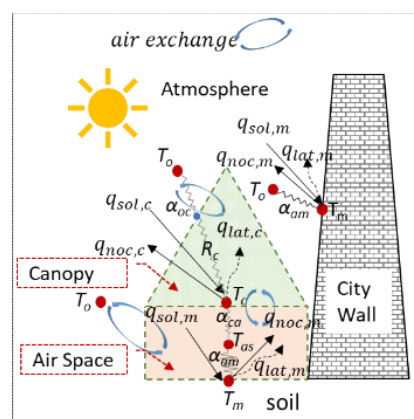

(a) Thermal nodal network

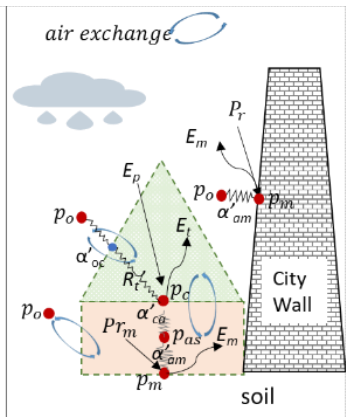

(b) Moisture nodal network

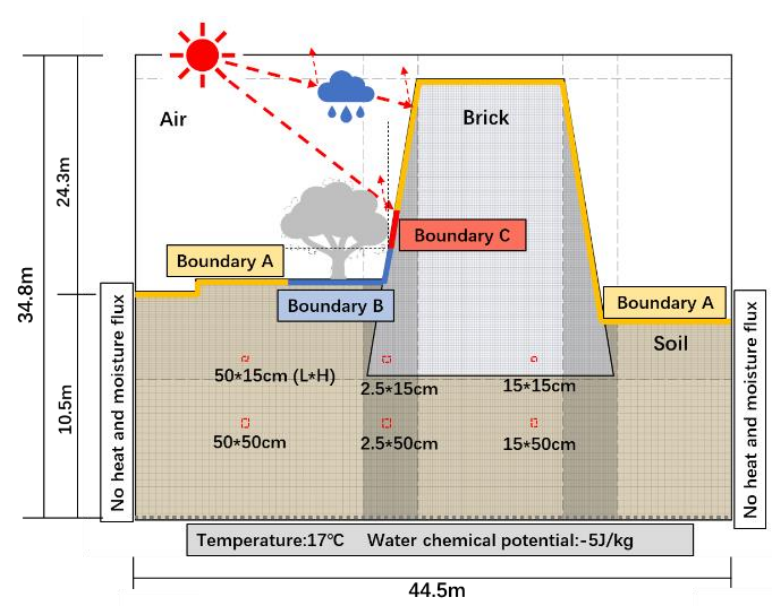

(c) The illustration of the calculation region and the boundary conditions

Fig. 2 Schematic diagram of heat and moisture transfer in plant model: (a) thermal nodal network; (b) moisture nodal network.; (c) the illustration of the calculation region and the boundary conditions.

\subsubsection{Air temperature and relative humidity under} the canopy 
Fig. 3 shows the measured air temperature and

324 relative humidity under the canopy at Site 1 along

325 with the meteorological (outdoor) data. During the

326 monitoring period (Jun. 2019 - Dec. 2019), the

327 temperature fluctuation range of the air under the

328 tree and outdoor air were $35.9^{\circ} \mathrm{C}\left(1.8^{\circ} \mathrm{C} \sim 37.7^{\circ} \mathrm{C}\right)$,

329 and $38.4{ }^{\circ} \mathrm{C}\left(1.6{ }^{\circ} \mathrm{C} \sim 40{ }^{\circ} \mathrm{C}\right)$, respectively. In

330 summer, the air temperature under the canopy was

331 lower than the outdoor air throughout the day, with

332 a maximum temperature difference of $6.1{ }^{\circ} \mathrm{C}$. In

333 addition, the relative humidity under the canopy was

334 higher than the outdoor air for most of the time. The

335 relative humidity difference was between $27 \% \sim 8 \%$.

\section{3.1.2 Surface temperature and water content}

\section{7 of City Wall}

338 Fig. 4a shows the measured surface temperatures

339 at shaded $\mathrm{H}_{1.2}, \mathrm{H}_{3.9}, \mathrm{H}_{5.4}$ and ground surface at Site

3401 and the unshaded $\mathrm{H}_{3.9}$ at Site 2. Part of the

341 temperature data was missing when the temperature
342 recorder equipment was not powered. In summer,

343 almost small differences between the daily

344 minimum temperatures and large differences

345 between the maximum values were seen on

346 measured points, while the temperature differences

347 decreased in winter. In addition, due to the low solar

348 altitude in winter, the measurement point at Site 2

349 was partly shaded by trees, and the temperature

350 fluctuation was similar with those at the shaded

351 points.

352 Fig. 4b shows the average water content of 10

353 horizontally consecutive bricks at three heights

$354\left(\mathrm{H}_{0.15}, \mathrm{H}_{1.2}\right.$, and $\left.\mathrm{H}_{2.1}\right)$ at Site 1. The water content at

355 the shaded surface decreased with height and

356 showed a similar fluctuation trend at the three

357 heights. During the monitoring period, the water

358 content was obviously affected by rainfall. The

359 water content was higher in rainy season (July and

360 August), while lower in arid season (September and

361 October).

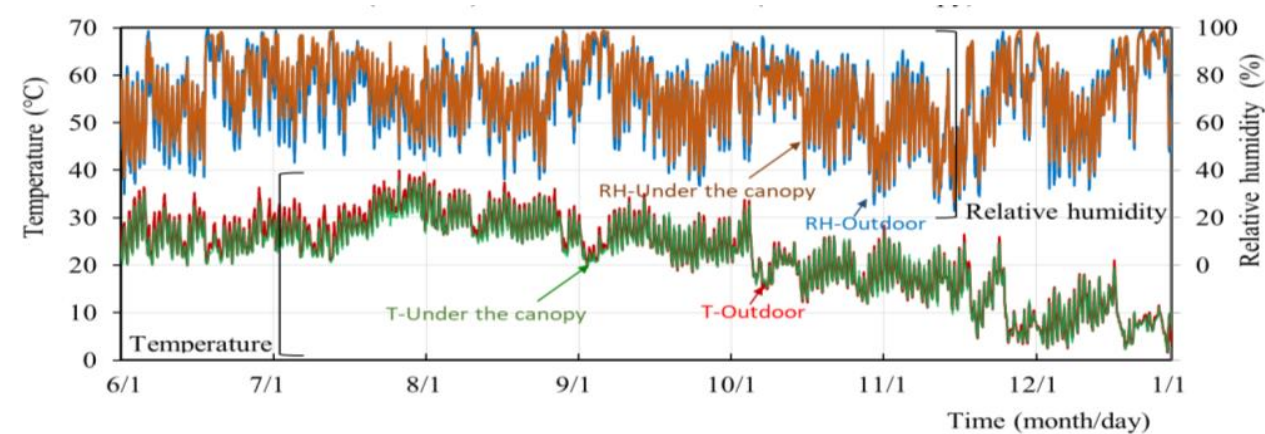

Fig. 3 Temperature and relative humidity under the canopy and at meteorological station (Jun. 2019 - Dec. 2019)

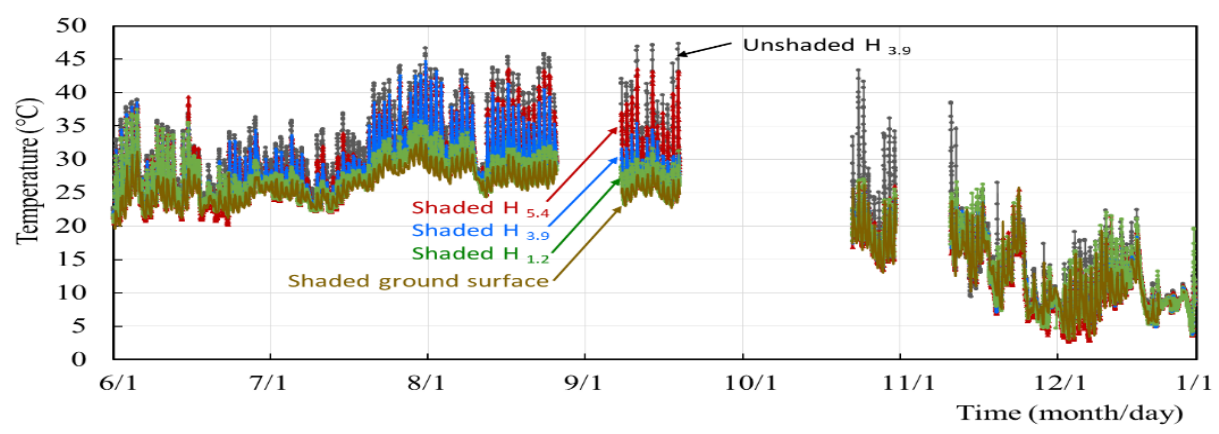

(a) 


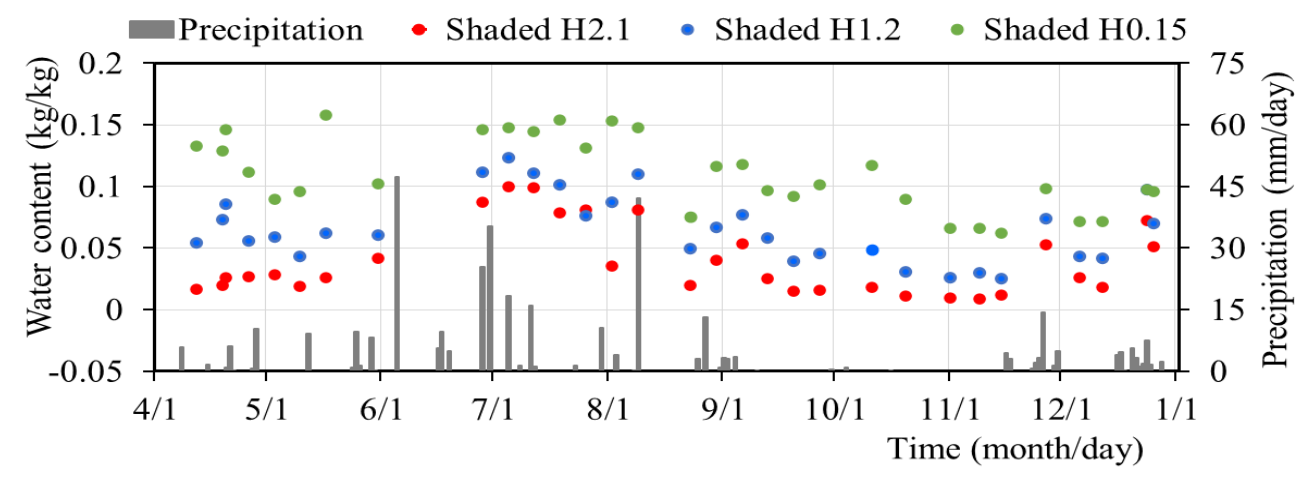

(b)

\section{$373 \quad 3.2$ Validation of proposed model}

374 A two-dimensional 'City Wall-plant' model was 375 set up by FORTRAN language to simulate the 376 shaded wall at Site 1 (Fig. 1a). Different interception 377 coefficients were used to represent the canopy 378 characteristics in the unshaded and shaded cases. 379 For a shaded case, the tree is evergreen with a height 380 of $7.5 \mathrm{~m}$, a canopy diameter of $7 \mathrm{~m}$, a distance of 3.5 $381 \mathrm{~m}$ to the City Wall; the canopy to radiation flux and 382 interception coefficient were assumed as $3830.85^{*} 0.5^{\left(h / h \_s h a d e\right)}$ (where $h \_$shade is the shadow 384 height on the wall surface and $h$ is the height above 385 the ground within the shadow range) and 0.8, 386 respectively. Whereas in unshaded case, both of 387 interception coefficients were 0 .

388 The simulated surface temperatures and water 389 content were compared with the measured results to 390 validate the two-dimensional 'City Wall-plant' 391 model.

\section{$392 \quad$ 3.2.1 Surface temperature}

393 Fig. 5 shows the measured and simulated surface 394 temperatures at shaded and unshaded H.9. $_{3}$. Fig. 5a 395 shows that simulated results agreed well with the 396 measured results at shaded $\mathrm{H}_{3.9}$ at Site 1. A linear 397 regression analysis was performed with the 398 measured and simulated results, and a good 399 correlation was obtained with slope 0.98 and 400 goodness-of-fit $0.98 \quad\left(\mathrm{y}=0.976 \mathrm{x} ; \mathrm{R}^{2}=0.9871 ; \mathrm{x}\right.$ : 401 measured values, $\mathrm{y}$ : simulated values).

402 Fig. 5 b shows the measured and simulated surface 403 temperatures at the unshaded $\mathrm{H}_{3.9}$ at Site 2. The 404 simulation results agreed well with the measured 405 values in summer but were slightly higher than the 406 measured in winter. This is probably because the 407 shade of the tree was not taken into consideration in
408 the simulation, despite that the solar altitude 409 decreased in winter and the measured point was 410 shaded by trees. Regardless, a linear regression 411 analysis with the measured and simulated values at 412 Site 2 shows good correlation between the simulated 413 and measured temperatures, with goodness-of-fit of 4140.92 and slope $1.03\left(y=1.0329 x ; R^{2}=0.9201 ; x\right.$ : 415 measured values, y: simulated values).

\section{$416 \quad$ 3.2.2 Water content}

417 Fig. 6 shows the simulated and measured water 418 content at shaded $\mathrm{H}_{0.15}, \mathrm{H}_{1.2}$, and $\mathrm{H}_{2.1}$ at Site 1. The 419 simulation results show that the annual water 420 content of $\mathrm{H}_{0.15}, \mathrm{H}_{1.2}$, and $\mathrm{H}_{2.1}$ fluctuated within $4210.15 \mathrm{~m}^{3} / \mathrm{m}^{3}-0.25 \mathrm{~m}^{3} / \mathrm{m}^{3}, 0-0.2 \mathrm{~m}^{3} / \mathrm{m}^{3}$, and $0-0.2 \mathrm{~m}^{3} / \mathrm{m}^{3}$. 422 In early July, the water content of the points was 423 higher due to the rain period; then, after the rain, the 424 water content showed an obvious downward trend. 425 Moreover, the water content at $\mathrm{H}_{0.15}, \mathrm{H}_{1.2}$, and $\mathrm{H}_{2.1}$ 426 in September to November (dry months) was 427 fluctuating within $0.1 \mathrm{~m}^{3} / \mathrm{m}^{3} \sim 0.2 \mathrm{~m}^{3} / \mathrm{m}^{3}, 0.05 \mathrm{~m}^{3} / \mathrm{m}^{3} \sim$ $428 \quad 0.1 \mathrm{~m}^{3} / \mathrm{m}^{3} \quad 0 \sim 0.05 \mathrm{~m}^{3} / \mathrm{m}^{3}$, respectively. The 429 simulation results could predict the fluctuation trend 430 of the characteristic points on the wall surface 431 subjected to rainfall. We analysed the consistency of 432 measured and simulated values by using the mean 433 absolute error (MAE) between the simulated and 434 measured values at three heights, $\mathrm{H}_{0.15}, \mathrm{H}_{1.2}$, and $\mathrm{H}_{2.1}$ 435 was $\quad 0.029 \mathrm{~m}^{3} / \mathrm{m}^{3}, \quad 0.036 \mathrm{~m}^{3} / \mathrm{m}^{3}, \quad 0.035 \mathrm{~m}^{3} / \mathrm{m}^{3}$, 436 respectively. The comparison between field and 437 simulated data shows that the simulated water 438 content was consistent with the measured result at 439 three points and it can reproduce the time profile in 440 the measured results.

441 It can be concluded that the simulated 442 temperatures and water content agreed well with the 443 measured results irrespective of shaded or unshaded 
444 conditions. Thus, the proposed 'City Wall-plant'

445 model can be used to examine the influence of the 448

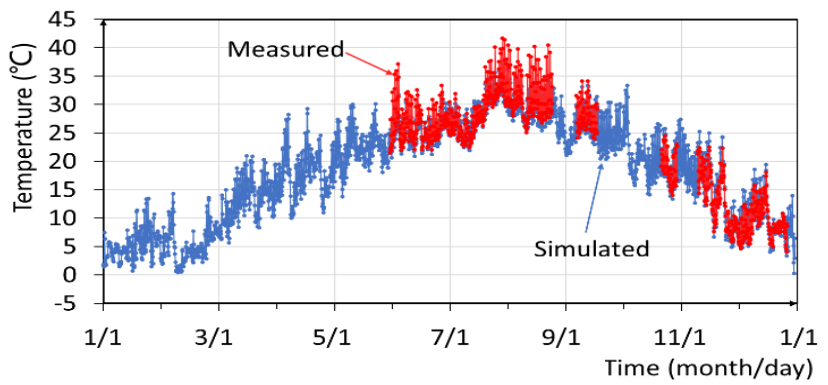

(a) Shaded $\mathrm{H}_{3.9}$ ( site 1)
446 surrounding trees on the hygrothermal fluctuations 447 and weathering of City Wall.

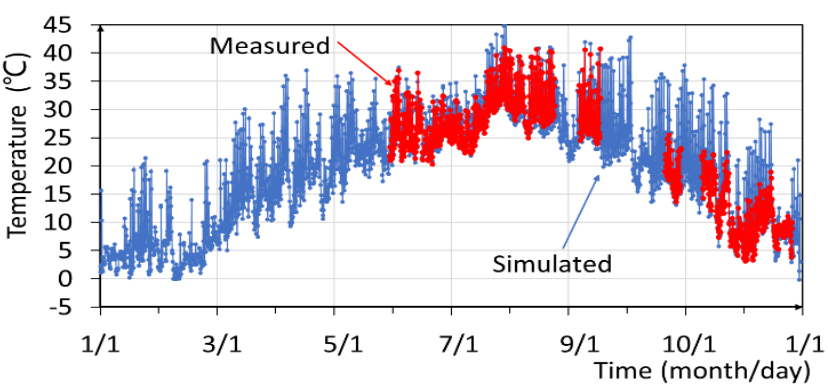

(b) Unshaded $\mathrm{H}_{3.9} \quad$ ( site 2)

Fig. 5 Comparison of measured and simulated surface temperatures: (a) Shaded $\mathrm{H}_{3.9}$; (b) Unshaded $\mathrm{H}_{3.9}$.

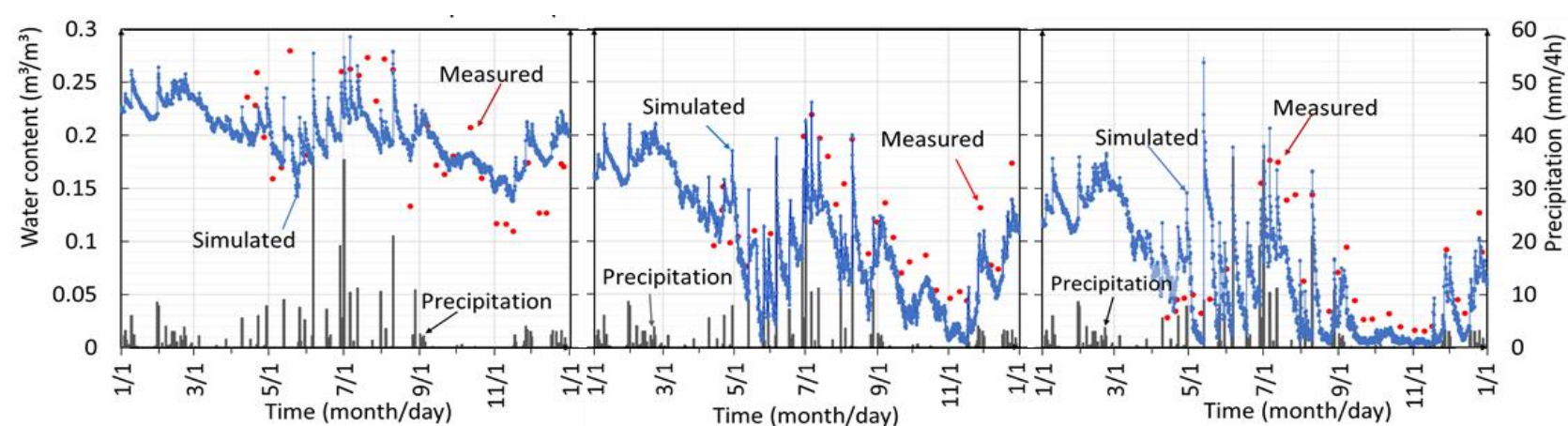

(a) (b)

(c)

Fig. 6 Comparison of measured and simulated water content at three shaded points: (a) $\mathrm{H}_{0.15}$; (b) $\mathrm{H}_{1.2}$; (c) $\mathrm{H}_{2.1}$.

\section{$451 \quad 3.3$ Calculated results}

452 The surface temperatures, water content at the

453 characteristic points (temperatures at $\mathrm{H}_{1.2}, \mathrm{H}_{3.9}, \mathrm{H}_{5.4}$,

454 and ground surface; water content at $\mathrm{H}_{0.15}, \mathrm{H}_{1.2}, \mathrm{H}_{2.1}$,

455 and ground surface) were calculated.

456 Fig. 7 shows the annual temperature fluctuations

457 at points $\mathrm{H}_{1.2}, \mathrm{H}_{3.9}, \mathrm{H}_{5.4}$, and ground surface in the

458 shaded and unshaded cases. The temperature

459 fluctuations in the unshaded case were larger than

460 those in the shaded case, with large difference in

461 maximum temperatures and small difference in

462 minimum temperatures.

463 Statistics in Table. 1 show that compared with the

464 unshaded case, the shaded surface showed smaller

465 temperature fluctuations, and the difference of the

466 maximum temperature between shaded and

467 unshaded cases decreased with height. The

468 maximum temperatures in the unshaded case was

469 higher than those in the shaded case by $9.7^{\circ} \mathrm{C}$ at

$470 \mathrm{H}_{1.2}, 7.4^{\circ} \mathrm{C}$ at $\mathrm{H}_{3.9}, 6.8{ }^{\circ} \mathrm{C}$ at $\mathrm{H}_{5.4}$, and $11.8{ }^{\circ} \mathrm{C}$ at

471 ground surface. The minimum temperatures in the

472 unshaded case was lower than those in the shaded

473 case by $0.8^{\circ} \mathrm{C}$ at $\mathrm{H}_{1.2}, 0.5^{\circ} \mathrm{C}$ at $\mathrm{H}_{3.9}, 0.5^{\circ} \mathrm{C}$ at $\mathrm{H}_{5.4}$,
474 and $1.9{ }^{\circ} \mathrm{C}$ at ground surface. Compared with the 475 unshaded surface, the shaded surface showed 476 smaller temperature fluctuations with the minimum 477 temperature increasing by $0.5 \sim 0.8^{\circ} \mathrm{C}$

478 Fig. 8 shows the water content at $\mathrm{H}_{0.15}, \mathrm{H}_{1.2}, \mathrm{H}_{2.1}$, 479 and ground surface between the shaded and 480 unshaded cases. The water content in the shaded 481 case was higher than that of the unshaded one 482 including the ground surface. This is mainly due to 483 the difference in the surface evaporation rate leading 484 to water content differences at the same height. The 485 water content decreased with height in both cases, 486 except that the water content at unshaded points $\mathrm{H}_{2.1}$ 487 and $\mathrm{H}_{1.2}$ was higher than that at point $\mathrm{H}_{0.15}$ in the 488 rainfall period around $13^{\text {th }}$ May and $31^{\text {st }}$ July. 489 Because of the heavy rainfall during this period (8.6 $490 \mathrm{~mm}$ in $25 \mathrm{~min}\left(13^{\text {th }}\right.$ May); $10.6 \mathrm{~mm}$ in $45 \mathrm{~min}\left(31^{\text {st }}\right.$ 491 July)), the bricks in unshaded case absorbed a large 492 amount of rainfall. Then, the water content at $\mathrm{H}_{0.15}$ 493 drained away faster than at $\mathrm{H}_{1.2}$ and $\mathrm{H}_{2.1}$, as point $494 \mathrm{H}_{0.15}$ was close to the ground and the moisture 495 conductivity of the soil was higher than that of brick. 496 Statistics in Table. 2 shows that compared with the 
497 unshaded case, the shaded surface showed smaller

498 water content fluctuations, and smaller standard

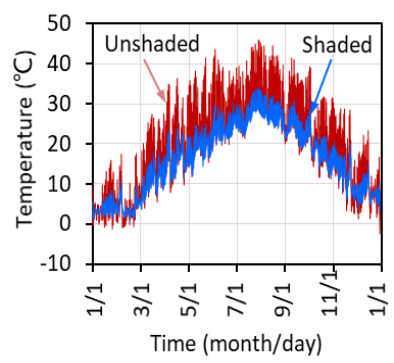

(a) Ground surface

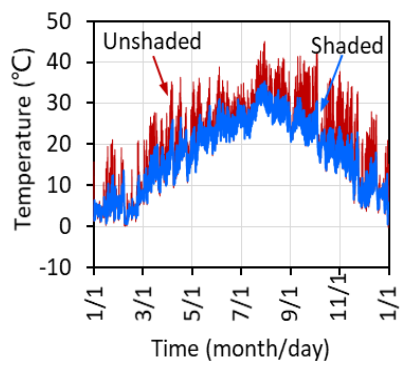

(b) $\mathrm{H}_{1.2}$
499 deviation by around $0.04 \mathrm{~m}^{3} / \mathrm{m}^{3}$ at $\mathrm{H}_{1.2}$ and ground 500 surface.

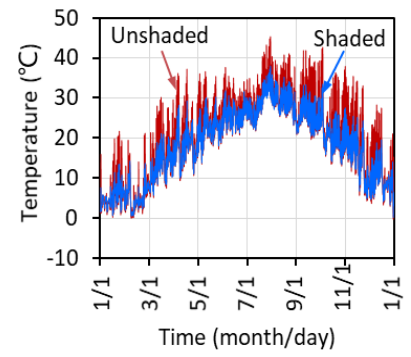

(c) $\mathrm{H}_{3.9}$

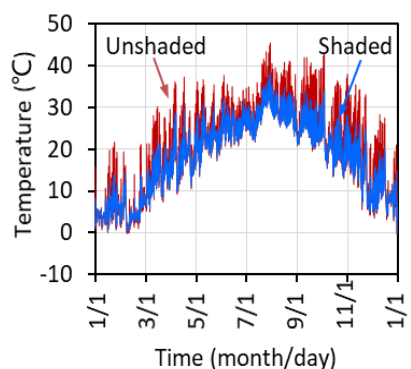

(d) $\mathrm{H}_{5.4}$
504

Table. 1 Statistics of simulated surface temperatures between shaded and unshaded cases.

\begin{tabular}{|c|c|c|c|c|c|c|c|c|c|}
\hline & & $\begin{array}{c}\text { Unshaded } \\
\left({ }^{\circ} \mathrm{C}\right)\end{array}$ & $\begin{array}{c}\text { Shaded } \\
\left({ }^{\circ} \mathbf{C}\right)\end{array}$ & $\begin{array}{c}\text { Difference } \\
\left({ }^{*} \mathbf{C}\right)\end{array}$ & & & $\begin{array}{c}\text { Unshaded } \\
\left({ }^{\circ} \mathbf{C}\right)\end{array}$ & $\begin{array}{c}\text { Shaded } \\
\left({ }^{\circ} \mathbf{C}\right)\end{array}$ & $\begin{array}{c}\text { Difference } \\
\left({ }^{\circ} \mathbf{C}\right)\end{array}$ \\
\hline \multirow{4}{*}{$\mathrm{H}_{1.2}$} & Max. & 45.0 & 35.3 & 9.7 & \multirow{4}{*}{$\mathrm{H}_{5.4}$} & Max. & 45.4 & 38.6 & 6.8 \\
\hline & Min. & -0.1 & 0.6 & -0.8 & & Min. & -0.2 & 0.3 & -0.5 \\
\hline & Ave. & 19.3 & 17.6 & 1.7 & & Ave. & 19.4 & 18.2 & 1.2 \\
\hline & Dev.* & 9.9 & 8.7 & 1.3 & & Dev.* & 10.0 & 9.0 & 1.0 \\
\hline \multirow{4}{*}{$\mathbf{H}_{3.9}$} & Max. & 45.4 & 38.0 & 7.4 & \multirow{4}{*}{ Ground surface } & Max. & 46.0 & 39.6 & 6.3 \\
\hline & Min. & -0.2 & 0.3 & -0.5 & & Min. & -2.3 & -0.3 & -1.9 \\
\hline & Ave. & 19.4 & 18.2 & 1.3 & & Ave. & 18.5 & 18.0 & 0.5 \\
\hline & Dev.* & 10.0 & 9.0 & 1.1 & & Dev.* & 10.77 & 8.59 & 2.2 \\
\hline
\end{tabular}

*Difference=Unshaded values -Shaded values; Dev.=The standard deviation

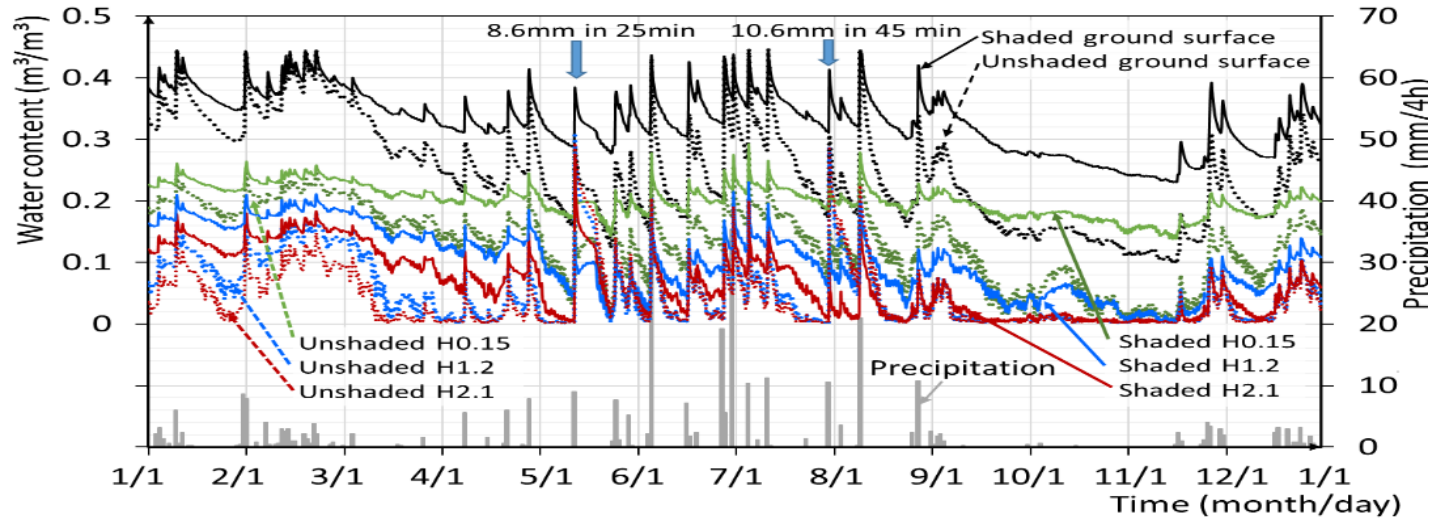

Fig. 8 Comparison of water content at points $\mathrm{H}_{0.15}, \mathrm{H}_{1.2}, \mathrm{H}_{2.1}$, and ground surface between shaded and unshaded cases.

Table. 2 Statistics of simulated water content between shaded and unshaded cases

\begin{tabular}{|c|c|c|c|c|c|c|c|c|c|}
\hline & & $\begin{array}{c}\text { Unshaded } \\
\left(\mathbf{m}^{3} / \mathbf{m}^{3}\right)\end{array}$ & $\begin{array}{l}\text { Shaded } \\
\left(\mathrm{m}^{3} / \mathrm{m}^{3}\right)\end{array}$ & $\begin{array}{c}\text { Difference }^{*} \\
\left(\mathrm{~m}^{3} / \mathrm{m}^{3}\right)\end{array}$ & & & $\begin{array}{c}\text { Unshaded } \\
\left(\mathbf{m}^{3} / \mathbf{m}^{3}\right)\end{array}$ & $\begin{array}{l}\text { Shaded } \\
\left(\mathrm{m}^{3} / \mathrm{m}^{3}\right)\end{array}$ & $\begin{array}{c}\text { Difference }^{*} \\
\left(\mathrm{~m}^{3} / \mathrm{m}^{3}\right)\end{array}$ \\
\hline \multirow{4}{*}{$\mathbf{H}_{1.2}$} & Max. & 0.278 & 0.293 & -0.015 & \multirow{4}{*}{$\mathbf{H}_{5.4}$} & Max. & 0.292 & 0.269 & 0.023 \\
\hline & Min. & 0.005 & 0.138 & -0.133 & & Min. & 0.001 & 0.002 & -0.001 \\
\hline & Ave. & 0.131 & 0.201 & -0.071 & & Ave. & 0.041 & 0.066 & -0.025 \\
\hline & Dev. & 0.061 & 0.025 & 0.036 & & Dev. & 0.048 & 0.052 & -0.004 \\
\hline \multirow{3}{*}{ H3.9 } & Max. & 0.303 & 0.231 & 0.073 & \multirow{3}{*}{ Ground surface } & Max. & 0.444 & 0.444 & 0.000 \\
\hline & Min. & 0.001 & 0.004 & -0.003 & & Min. & 0.098 & 0.230 & -0.132 \\
\hline & Ave. & 0.051 & 0.102 & -0.051 & & Ave. & 0.246 & 0.332 & -0.085 \\
\hline
\end{tabular}




\section{Discussion}

514 In this study, the hygrothermal behaviour of an 515 ancient city wall was evaluated by combining field 516 measurements with numerical simulation,. 517 Hygrothermal regulation via plantation/trees was 518 achievable; the influence of urban trees on the 519 sustainable protection of an ancient city wall

520 (Nanjng City Wall) was quantitatively assessed.

5214.1 The impact of trees on the freeze-thaw cycle of 522 City Wall

523 To evaluate the impact of the trees/plantation on 524 the freeze-thaw cycle of building elements (ancient 525 City Wall of Nanjing as a point of reference), the 526 'frequency' and 'duration' of these phenomena were 527 assumed as key evaluation indexes. 'Frequency'

528 refers to the number of times the temperature

529 crossed the freezing point $0{ }^{\circ} \mathrm{C}$; 'duration' refers to

530 the total time that temperatures remained below $0{ }^{\circ} \mathrm{C}$

531 in the year.

532 The freezing-thawing frequency and duration at 533 heights of $\mathrm{H}_{1.2}, \mathrm{H}_{3.9}$, and $\mathrm{H}_{5.4}$ between shaded and 534 unshaded cases were compared. It should be 535 remarked that not all episodes of negative 536 temperatures resulted in ice formation [42]. In this 537 paper, $0{ }^{\circ} \mathrm{C}$ is used as the approximate critical value 538 to count freezing events. Because the annual 539 average outdoor temperature in 2019 was higher 540 than that in a typical year, it is likely that the 541 freezing-thawing cycles had less impact in 2019 542 than in a typical year. However, the influence of the 543 trees was obvious. For a year, freezing events 544 occurred five times with 5.4 hours of freezing at 545 point $\mathrm{H}_{1.2}$ as well as six times with 13.9 hours at 546 points $\mathrm{H}_{3.9}$ and $\mathrm{H}_{5.4}$ on unshaded surfaces, 547 respectively, compared to no frost in the shaded 548 case.

549 The freezing-thawing cycle is a threshold-driven 550 process. Therefore, even a slight change to the wall 551 microclimate can have significant consequences on 552 frost-driven deterioration. The simulation of 553 freezing-thawing cycles showed that the freezing554 thawing frequency in the shaded case decreased 555 compared with the unshaded. The decisive factors 556 of the wall surface temperature are the solar 557 radiation absorbed and nocturnal radiation emitted 558 by the wall, which are influenced by the trees [ 43 , 559 44]. The net radiation in the shaded case was larger
560 (small negative) at night, although less (small 561 positive) during daytime than that in the unshaded 562 case in the winter month (Feb.) (Fig. 10), which led 563 to a higher minimum temperature in the shaded case. 564 The water content also affects the temperature of the 565 wall surface due to evaporative cooling. It can be 566 seen from Table. 3 that the evaporation amount in 567 the unshaded case was slightly higher than the 568 shaded, which leads to more heat loss by 569 evaporative cooling and lower temperatures in the 570 unshaded case.

571 Considering the above-mentioned results, the 572 evergreen trees can be judged to reduce the risk of 573 freezing-thawing cycles.

5744.2 The impact of trees on the salt crystallization 575 risk of City Wall

576 The crystallization pressure of soluble salts is one 577 of the most important deteriorating factors that 578 affects the durability of porous materials $[45,46]$ 579 .Salt decay includes the process of salt 580 crystallization on the surface of a porous material 581 (efflorescence) and the process of crystallization 582 within the porous system (subflorescence) [47].

\subsubsection{Salt crystallization (efflorescence)}

The amount of evaporation is closely related to the amount of salt that migrates to the surface $588\left(\mathrm{H}_{1.2}, \mathrm{H}_{3.9}\right.$, and $\left.\mathrm{H}_{5.4}\right)$. The amount of annual 589 evaporation in the shaded case was lower than the 590 unshaded by $18 \%$ at $\mathrm{H}_{1.2}, 10 \%$ at $\mathrm{H}_{3.9}$, and $8 \%$ at $591 \quad \mathrm{H}_{5.4}$. The monthly evaporation at three heights $\left(\mathrm{H}_{1.2}\right.$, $592 \mathrm{H}_{3.9}$, and $\left.\mathrm{H}_{5.4}\right)$ in shaded and unshaded cases is 593 shown in Fig. 9. The monthly evaporation at three 594 heights $\left(\mathrm{H}_{1.2}, \mathrm{H}_{3.9}\right.$, and $\left.\mathrm{H}_{5.4}\right)$ in unshaded case was 595 greater than the shaded, except for point $\mathrm{H}_{1.2}$ in 596 September, October, and November and points $\mathrm{H}_{3.9}$ 597 and $\mathrm{H}_{5.4}$ in March and April. Table. 4 shows the 598 monthly evaporation at the shaded point $\mathrm{H}_{1.2}$ was 599 about 3\% 44\% less than the unshaded from 600 December to September, while $31 \%$ more in 601 October and $67 \%$ more in November. This is mainly 602 due to the higher temperature leading to rapid 603 evaporation and a decrease in water content of 604 bricks in the unshaded case. Due to the long-term 605 drought from September to November, there was no 606 water to make up for the loss from evaporation in 
607 the unshaded case, whereas a relatively wet wall in

608 the shaded case could provide more water for

609 evaporation. The same condition happened in

610 March and April at heights $\mathrm{H}_{3.9}$ and $\mathrm{H}_{5.4}$.

611 A large amount of evaporation took place in the

612 unshaded case compared with the shaded case

613 (Table. 3), meaning that there were higher

614 possibilities of salt accumulation on the surface. In

615 such a situation, it is likely that the trees can reduce

616 efflorescence with their shade.

617 4.2.2 Crystallization within the porous system

618 (subflorescence)

619 The crystallization pressure of soluble salts is one

620 of the most important deteriorating factors that

621 affect the durability of porous materials regarding

622 the process of subflorescence [45]. Sodium sulfate

623 is a destructive soluble salt existing often in porous

624 materials; therefore, the risk of salt damage of the

625 City Wall was studied with sodium sulfate. The

626 sodium sulfate assumes a different phase depending

627 on temperature and humidity, that is, sodium sulfate

628 solution (liquid), thenardite (solid), and mirabilite

629 (solid).

630 The impact of trees on the building wall (as City

631 Wall Nanjing reference) deterioration risk from salt

632 crystallization was evaluated using a phase diagram

633 for sodium sulfate [46]. The daily average

634 temperature and relative humidity at three heights

$635 \mathrm{H}_{1.2}, \mathrm{H}_{3.9}$, and $\mathrm{H}_{5.4}$ on the shaded and unshaded

636 surfaces in the year of 2019 are plotted on the phase

637 equilibrium chart in Fig. 11. The black lines divide

638 the coordinate area into three parts: sodium sulfate
639 solution (liquid), thenardite (solid), and mirabilite

640 (solid), corresponding to the phases of sodium

641 sulfate under different temperature and humidity

642 conditions. The phase change between liquid and

643 solid or between solid (Mirabilite) and solid

644 (Thenardite) can be related to crystallization

645 pressure, which may adversely affect the structure

646 of porous materials.

647 As seen in Fig. 11a, the lines that connect 648 consecutive days are mostly located in a single 649 phase (solution) for the shaded $\mathrm{H}_{1.2}$, but located in 650 three phases for the unshaded $\mathrm{H}_{1.2}$. The unshaded

651 case may lead to deterioration by salt crystallization,

652 phenomenon with no serious risks for the shaded

653 case. For the points $\mathrm{H}_{3.9}, \mathrm{H}_{5.4}$, the lines that connect

654 consecutive days for both shaded and unshaded

655 cases appear to be very similar., this stands for the

656 frequency of the connecting lines crossing the

657 boundary between different phases, phenomenon

658 that occurered significantly more frequently for the

659 unshaded surface as compared to the shaded one.

660 This reveals the higher probability of salt

661 crystallization in the unshaded case compared to the

662 shaded case, with the strongest influence at $\mathrm{H}_{1.2}$ and

663 the weakest at $\mathrm{H}_{5.4}$, which indicate the influence of

664 trees on reducing the risk of crystallization for the

665 City Wall.

666 To evaluate the supersaturation and 667 crystallization pressure, transient moisture (liquid 668 and vapor) transfer and phase change processes of 669 the salt and moisture must in detail be taken into 670 consideration. This is a future work. 671

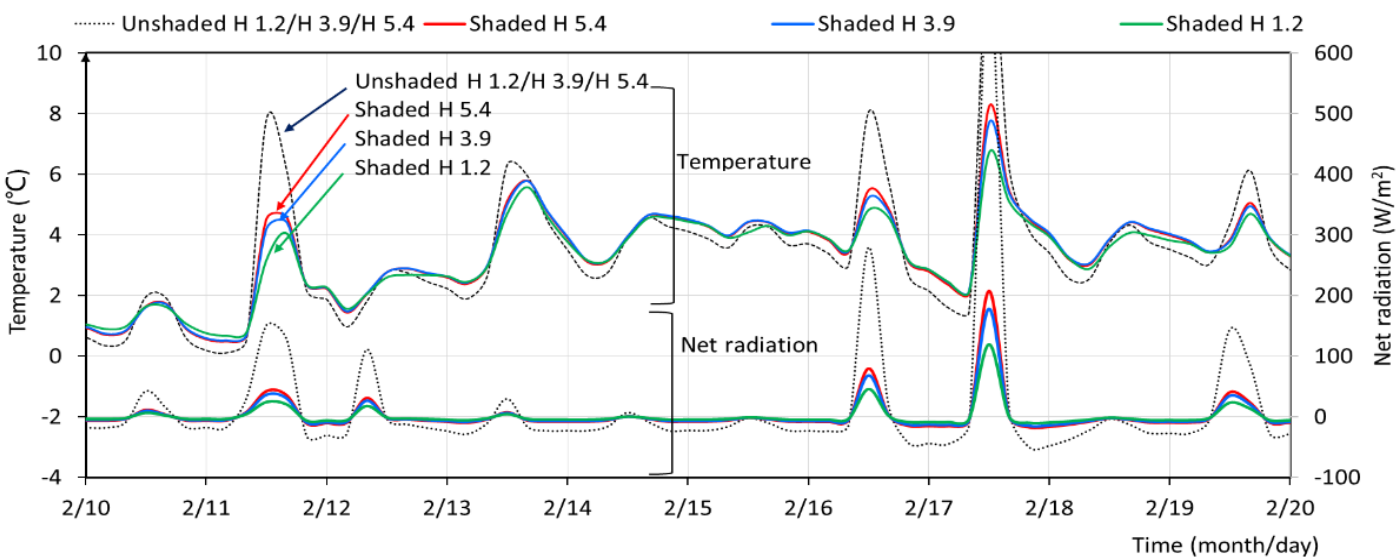

Fig. 10 Comparison of net radiation absorbed by the wall surface at three heights $\left(\mathrm{H}_{1.2}, \mathrm{H}_{3.9}\right.$, and $\left.\mathrm{H}_{5.4}\right)$. 
Table. 3 Comparison of annual evaporation at heights $\mathrm{H}_{1.2}, \mathrm{H}_{3.9}$, and $\mathrm{H}_{5.4}$.

\begin{tabular}{cccc}
\hline Total annual evaporation & $\mathbf{H}_{1.2}$ & $\mathbf{H}_{\mathbf{3 . 9}}$ & $\mathbf{H}_{\mathbf{5 . 4}}$ \\
\hline Unshaded $\left(\mathbf{k g} / \mathbf{m}^{2}\right)$ & 236.9 & 203.1 & 202.8 \\
Shaded $\left(\mathbf{k g} / \mathbf{m}^{2}\right)$ & 193.2 & 182.0 & 185.6 \\
Percentage reduction* & $18 \%$ & $10 \%$ & $8 \%$ \\
\hline
\end{tabular}

* Percentage reduction $=($ Unshaded - Shaded $) /$ Unshaded

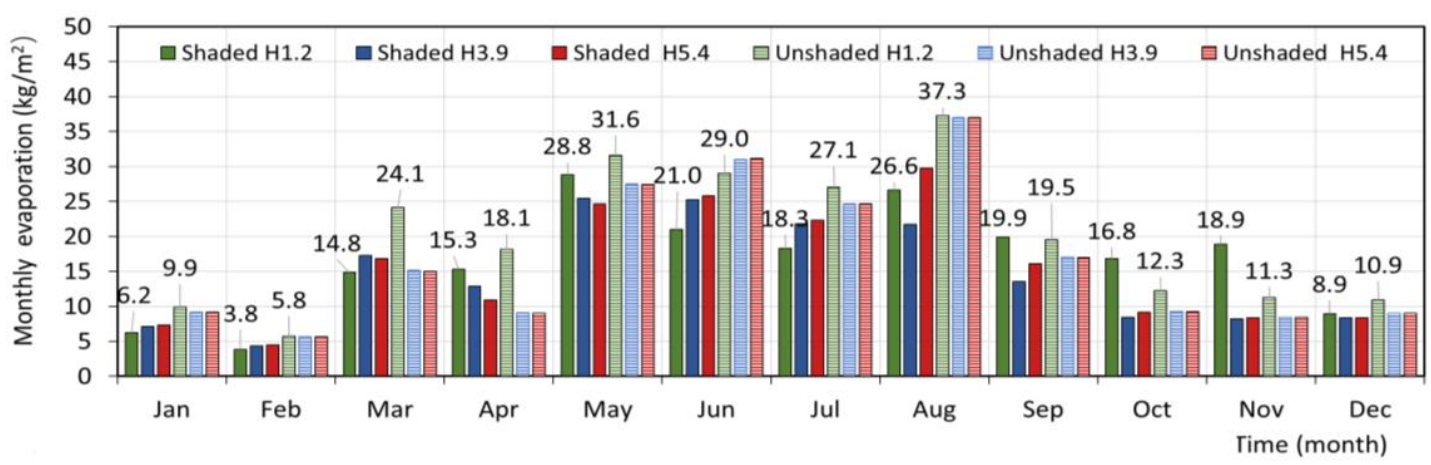

\subsection{The impact of characteristics trees}

683 The comparison of simulated results indicated the 684 influence of trees on surface microclimates of City 685 Wall. The temperature and water content on the 686 shaded surface showed less fluctuations as compared 687 with the unshaded one. In addition, evergreen trees 688 (Osmanthus) can effectively reduce the amount of 689 evaporation, the risk of freeze-thaw cycles, and salt

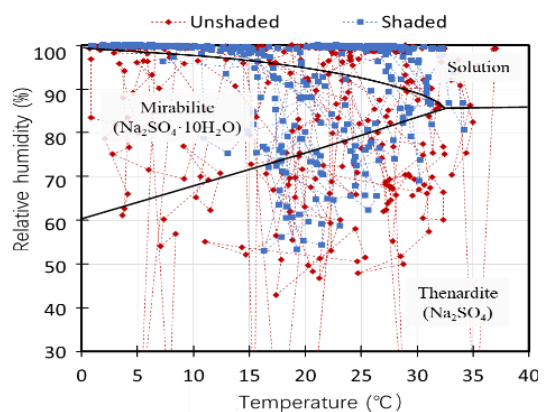

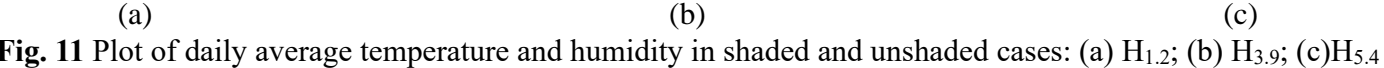

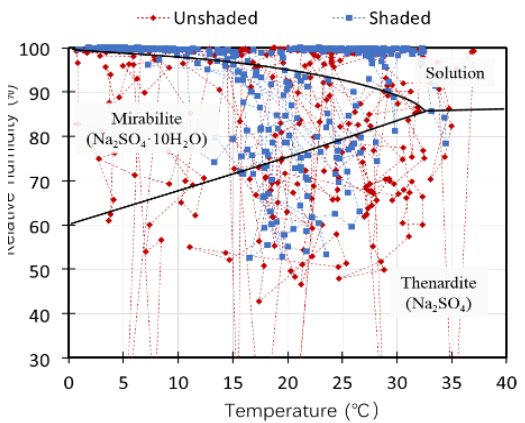

(c)
690 crystallization on the shaded surface. Among the 691 studied three heights, the lower part of City Wall was 692 the optimum in terms of minimizing weathering risk. 693 This is mainly due to the better shading effect of trees 694 on the low part. It can be said that the shading effect 695 of trees is positively correlated with the mitigation of 696 weathering on the wall surface.

697 The shading effect of trees is closely related to the 698 canopy structure and tree speciation. The efficacy of 
699 tree shading has been previously investigated

700 involving different tree species with specific

701 characteristics such as leaf size and leaf area index

702 (LAI) [48]. It was found that trees with large leaves

703 or a large leaf area index could provide with better

704 shading [49], as expected. In addition, trees can be

705 categorized into evergreen and deciduous trees. As

706 deciduous trees in winter may have the similar effect

707 with the unshaded case, it can be assumed that

708 deciduous trees are less effective than evergreen trees

709 in mitigating surface weathering of City Wall.

710 Except of the hygrothermally regulated beneficial

711 for the heritage result, due to the tree leaves and

712 branches, root growth also bears potential risks

713 rendering the heritage vulnerable [50]. Therefore, a

714 comprehensive risk assessment of the potential

715 buildings' deterioration and trees' protection must be

716 undertaken prior plant management activities and

717 interventions in heritage sites.

\section{Conclusion}

719 This study, by involving actual physicochemical

720 measurements and simulation intended to examine

721 the influence of trees on the conservational status and

722 the surface weathering of heritage sites. The City

723 Wall of Nanjing, China was used a point of reference.

724 (1) The impact of trees on the hygrothermal

725 characteristics of the wall's surface was preliminarily

726 evaluated via actual field measurements. The

727 measured results revealed that the trees weaken the

728 thermal stress on the wall.

729 (2) To evaluate the impact of the trees on the 730 surface weathering of the City Wall, a 'City Wall-

731 plant' model was developed and trialled. The good

732 agreement between actual-validation data and the

733 ability of the model to respond to diurnal and seasonal

734 variations proved the robustness of the model.

735 (3) The impact of trees on the surface weathering

736 of the City Wall was examined using the proposed 774

\section{Appendix A. Nomenclature}

\section{Nomenclature}

$R_{v} \quad$ the gas constant of water $\left(R_{v}=R / M_{v}\right)$

$R \quad$ the universal gas constant $\left[\mathrm{Pa} \cdot \mathrm{m}^{3} / \mathrm{kmol} \cdot \mathrm{K}\right]$

$M_{v} \quad$ molar weight of water $[\mathrm{kg} / \mathrm{kmol}]$

$h$ the relative humidity.

$\rho_{w} \quad$ water density $\left[\mathrm{kg} / \mathrm{m}^{3}\right]$

$\Psi \quad$ the volumetric water content $\left[\mathrm{m}^{3} / \mathrm{m}^{3}\right]$

$n \quad$ unit vector in the direction of gravity

$q$ heat flux $\left[\mathrm{W} / \mathrm{m}^{2}\right]$
737 model. Compared with the unshaded surface, the 738 shaded surface exhibited i) smaller temperature 739 fluctuations with the minimum temperature 740 increasing by $0.5 \sim 0.8^{\circ} \mathrm{C}$, ii) smaller water content 741 fluctuations with the standard deviation decreasing 742 by $0 \sim 0.04 \mathrm{~m}^{3} / \mathrm{m}^{3}$.

743 In addition, the shaded case showed that 744 evergreen trees can effectively reduce the 745 evaporation rate by $8 \sim 18 \%$, and the risk of 746 deterioration due to efflorescence, subflorescence, 747 and freeze-thaw cycles on the wall surfaces.

748 (5) Deciduous trees in winter, may have a similar 749 shading effect with that evaluated at the unshaded 750 case. Henc, the deciduous trees are supposed to be 751 less effective than the evergreen ones in mitigating 752 surface weathering.

753 By conducting this study, we found that the trees 754 have a significant influence on the microenvironment 755 and a positive effect in buffering the surface 756 weathering of the cultural heritages. This study 757 provides a basis for the landscape design around the 758 City Wall, and presents promising possibility for 759 more environmentally sustainable approaches to the 760 conservation of exposed and immovable historical 761 sites.

\section{Declaration of Competing Interests}

763 The author(s) declare no potential conflicts of 764 interest with respect to the research, authorship, 765 and/or publication of this article.

\section{Acknowledgements}

767 This research has been funded by the National 768 Nature Science Foundation of China (Grant No. 769 51878140); the China National Key R\&D Program 770 during the 13th Five-year Plan Period (No. 771 2019YFC1520900). This work was also supported by 772 the Nanjing City Wall Protection and Management 773 Centre. $c \rho \quad$ specific heat capacity $\left[\mathrm{J} /\left(\mathrm{m}^{3} \mathrm{~K}\right)\right]$

$c_{a}^{\prime} \quad$ moisture capacity of the air $\left[\mathrm{kg} /\left(\mathrm{m}^{3} \mathrm{~Pa}\right)\right]$

$V \quad$ volume $\left[\mathrm{m}^{3}\right]$

$\rho \quad$ density $\left[\mathrm{kg} / \mathrm{m}^{3}\right]$

$\beta \quad$ evaporation efficiency of vegetation [-]

$C_{h} \quad$ coefficient of volume movement [-]

$U$ wind speed [m/s]

$S_{h} \quad$ specific humidity $[\mathrm{kg} / \mathrm{kg}]$ 


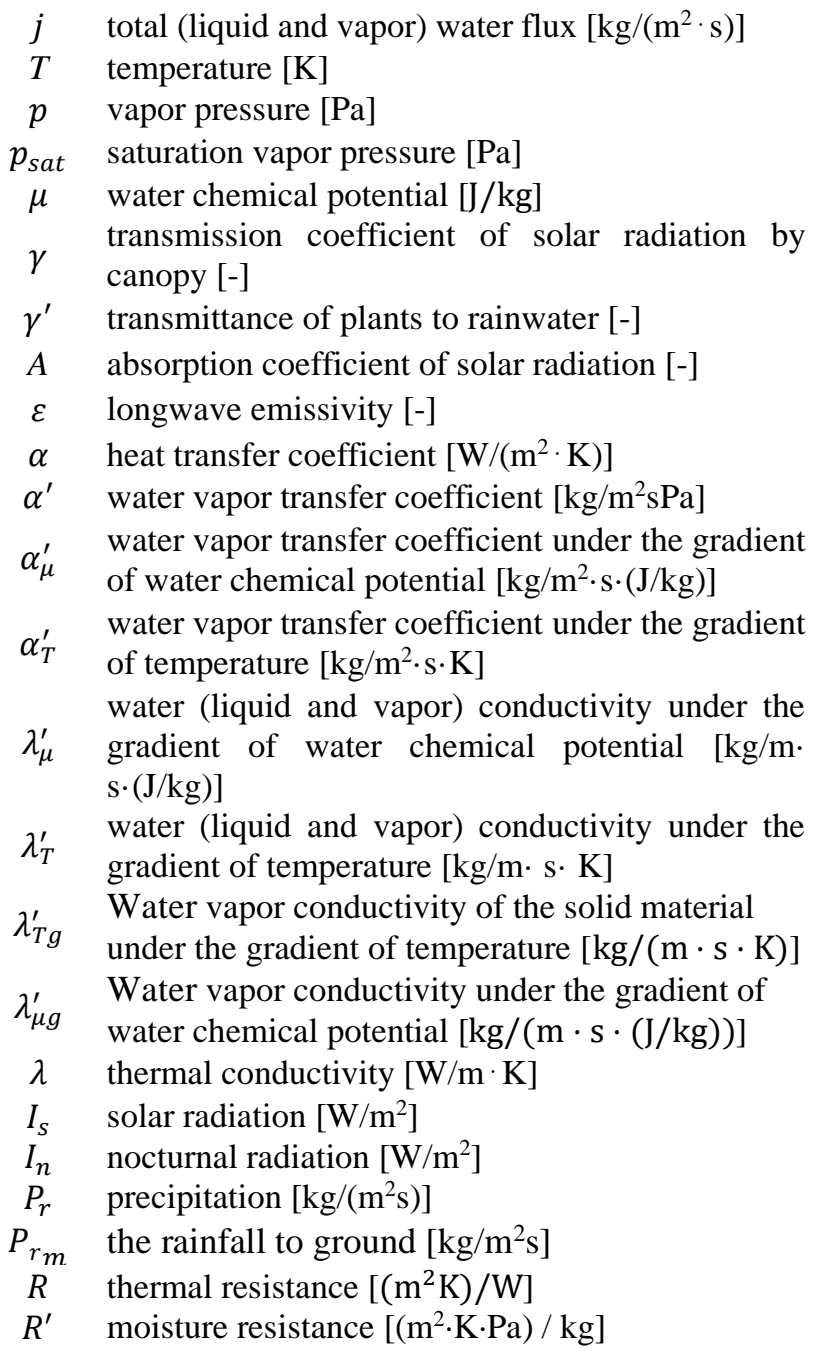

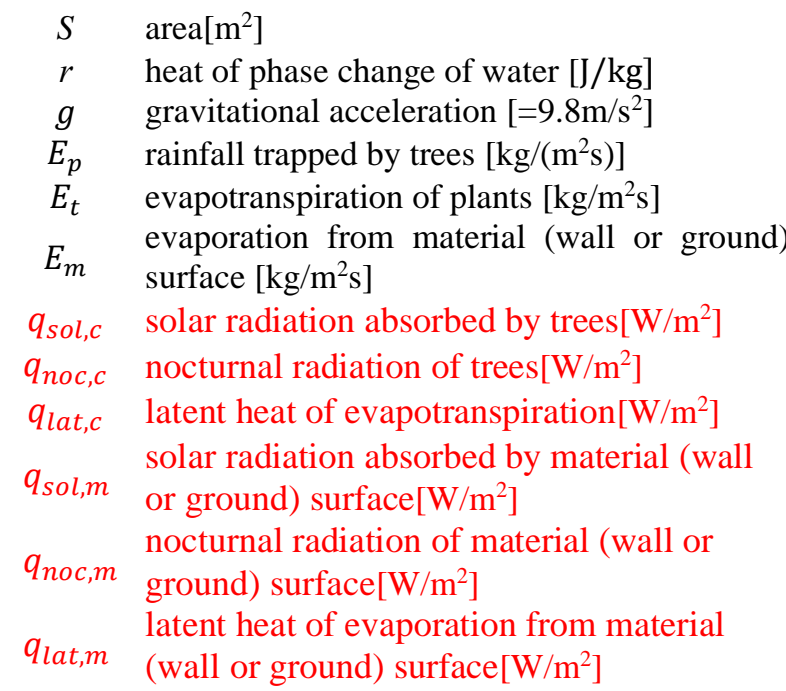

\section{Subscripts}

a air

$o$ outdoor

$s \quad$ surface

c canopy

as air space

$m$ material (wall or ground)

sol solar radiation

noc nocturnal radiation

lat latent heat

ex air exchange

$o c$ the outdoor air -canopy surface

ca the canopy-air space surface

am the air space-material (wall or ground) surface

\section{Appendix B. Plant model}

The plant model was based on the plant model by Kondou [41]. The equations of heat and moisture balance in plant model are as follows:

1. Heat balance of the canopy cell:

Where,

$$
\begin{gathered}
(c \rho)_{a} \cdot V_{c} \cdot \frac{\partial T}{\partial t}=\left\{\frac{\left(T_{o}-T_{c}\right)}{\left(1 / \alpha_{o c}+R_{c}\right)}+q_{\text {sol, } c}-q_{n o c, c}-q_{\text {lat, }}-\alpha_{c a} \cdot\left(T_{c}-T_{a s}\right)\right\} \cdot S+q_{e x, c} \\
q_{\text {sol, } c}=I_{\text {sol }} \cdot(1-\gamma) \cdot A_{c} \\
q_{l a t, c}=r \cdot\left(E_{t}+E_{p}\right) \\
q_{n o c, c}=\varepsilon_{c} \cdot I_{n o c}
\end{gathered}
$$

2. Heat balance of the air space under the canopy:

$$
(c \rho)_{\mathrm{a}} \cdot V_{a s} \cdot \frac{\partial T}{\partial t}=\alpha_{c a} \cdot\left(T_{c}-T_{a s}\right) \cdot S-\sum_{1}^{\mathrm{m} 1} \alpha_{a m} \cdot\left(T_{a s}-T_{m, i}\right) \cdot S_{i}+q_{e x, a s}
$$

3. Moisture balance of the canopy cell:

$$
C_{a}^{\prime} \cdot V_{c} \frac{\partial p}{\partial t}=\left\{\frac{\left(p_{o}-p_{c}\right)}{\left(1 / \alpha_{o c}^{\prime}+R_{c}^{\prime}\right)}+E_{p}+E_{t}-\alpha_{c a}^{\prime} \cdot\left(p_{c}-p_{a s}\right)\right\} \cdot S+j_{e x, c}
$$

4. Moisture balance of the air space under the canopy:

$$
C_{a}^{\prime} \cdot V_{a s} \frac{\partial p}{\partial t}=\sum_{l}^{m 2} E_{m, i} \cdot S_{i}+j_{e x, a s}
$$

Where,

$$
\begin{gathered}
E_{t}=\rho \beta C_{h} U \cdot\left(\frac{\partial S_{h}}{\partial P}\right) \cdot\left(p_{s a t}\left(T_{c}\right)-p_{o}\right) \\
E_{P}=(1-\gamma) \cdot P_{r}
\end{gathered}
$$




\section{References}

786 011 84(2015) 106343 106773
[1] S.A.C.O. United Nations Educational, The Great Wall. 1987. https://whc.unesco.org/en/list/438

[2] A.B. Salman, F.M. Howari, M.M. El-Sankary, A.M. Wali, M.M. Saleh, Environmental impact and natural hazards on Kharga Oasis monumental sites, Western Desert of Egypt. J. Afr Earth Sci. 58(2010) 341-353. 10.1016/j.jafrearsci.2010.03.

[3] M. Saba, E.E. Quiñones-Bolaños,H.F. Martínez Batista, Impact of environmental factors on the deterioration of the Wall of Cartagena de Indias. J. Cult Herit. 39(2019) 305-313. 10.1016/j.culher. 2019. 03. 001

[4] P. Jin, Y. Zhang, S. Wang, X. Yang,M. Zhang, Characterization of the superficial weathering of bricks on the City Wall of Xi' an, China. Constr Build Mater. 149(2017) 139-148. https://doi.org/10.1016/j.conbuildmat.2017.05.045

[5] Z. Zhang, Weathering mechanism and prevention methods of ancient brick in Pingyao city, Shaanxi province, China (in Chinese). Journal of Engineering Geology. 25(2017) 619-629.

[6] T. Waragai, Y. Hiki, Influence of microclimate on the directional dependence of sandstone pillar weathering in Angkor Wat temple, Cambodia. Prog. Earth Planet. Sc.. 6(2019). 10.1186/s40645019-0254-5

[7] A. Erkal, D. D Ayala,L. Sequeira, Assessment of wind-driven rain impact, related surface erosion and surface strength reduction of historic building materials. Build Environ. 57(2012) 336-348. 10.1016/j.buildenv.2012.05.004

[8] D.D. Ayala,Y.D. Aktas, Moisture dynamics in the masonry fabric of historic buildings subjected to wind-driven rain and flooding. Build Environ. 104(2016) 208-220.

[9] M. Uranjek,V. Bokan-Bosiljkov, Influence of freeze - thaw cycles on mechanical properties of historical brick masonry. Constr Build Mater. 416-428 https://doi.org/10.1016/j.conbuildmat.2015.03.077

[10] C. Feng, S. Roels,H. Janssen, Towards a more representative assessment of frost damage to porous building materials. Build Environ. 164(2019) 106343. 10.1016/j.buildenv.2019.

[11] X. Zhou, J. Carmeliet,D. Derome, Assessment of risk of freeze-thaw damage in internally insulated masonry in a changing climate. Build Environ. 175(2020) 106773. 10.1016/j.buildenv.2020.

[12] P. Merello, Á. Fernández-Navajas, J. CurielEsparza, M. Zarzo,F. García-Diego, Characterisation of thermo-hygrometric conditions of an archaeological site affected by unlike boundary weather conditions. Build Environ. 76(2014) 125-133. 10.1016/j.buildenv.2014.03. 009

[13] Y. Li, D. Ogura, S. Hokoi, J. Wang,T. Ishizaki, Predicting Hygrothermal Behavior of an Underground Stone Chamber with 3-D Modeling to Restrain Water-Related Damage to Mural Paintings. J. Asian Archit. Build.. 13(2014) 499506. https://doi.org/10.3130/jaabe.13.499

[14] Y. Li, Z. Huang, E. Petropoulos, Y. Ma,Y. Shen, Humidity governs the wallinhabiting fungal community composition in a 1600-year tomb of emperor Yang. Sci. Rep.-Uk. 10(2020) 8421. https://doi.org/10.1038/s41598-020-65478-Z

[15] Y. Li, R. Wu, H. Xie, G. Zhao, X. Dang,S. Hokoi, Water film in very high humidity inhibits mold growth on the damp surface of soil ruins. Build Environ. 181(2020) 107073. https://doi.org/10.1016/j.buildenv.2020.107073

[16] Y. Li, Y. Feng, Z. Kong,S. Hokoi, Optimization and Assessment of the Protective Shed of the Eastern Wu Tomb. Energies. 13(2020) 1652.

[17] T. Lamhasni, H. El-Marjaoui, A. El Bakkali, S.A. Lyazidi, M. Haddad, A. Ben-Ncer, F. Benyaich, A. Bonazza,M. Tahri, Air pollution impact on architectural heritage of Morocco: Combination of synchronous fluorescence and ATR-FTIR spectroscopies for the analyses of black crusts deposits. Chemosphere. 225(2019) 517-523. https://doi.org/10.1016/j.chemosphere.2019.03.10 9

[18] V. Comite, M. Álvarez De Buergo, D. Barca, C.M. Belfiore, A. Bonazza, M.F. La Russa, A. Pezzino, L. Randazzo,S.A. Ruffolo, Damage monitoring on carbonate stones: Field exposure tests contributing to pollution impact evaluation in two Italian sites. Constr Build Mater. 152(2017) 907-922. https://doi.org/10.1016/j.conbuildmat.2017.07.048

[19] L. Kong, K.K. Lau, C. Yuan, Y. Chen, Y. Xu, C. Ren,E. Ng, Regulation of outdoor thermal comfort by trees in Hong Kong. Sustain. Cities Soc.. 31(2017) 12-25. 10.1016/j.scs.2017.01.018

[20] M.A. Rahman, L.M.F. Stratopoulos, A. MoserReischl, T. Zölch, K. Häberle, T. Rötzer, H. Pretzsch,S. Pauleit, Traits of trees for cooling urban heat islands: A meta-analysis. Build Environ. 170(2020) 106606. 10.1016/j.buildenv.2019. 106606

[21] R. Berry, S.J. Livesley,L. Aye, Tree canopy shade impacts on solar irradiance received by building walls and their surface temperature. Build Environ. 69(2013) 91-100. https://doi.org/10.1016/ j. buildenv.2013.07.009

[22] L. Shashua-Bar,M.E. Hoffman, Vegetation as a climatic component in the design of an urban street: An empirical model for predicting the cooling effect of urban green areas with trees. Energ 
Buildings.

31(2000)

221-235. https://doi.org/10.1016/S0378-7788(99)00018-3

[23] B. Jaafar, I. Said, M.H. Rasidi, F.O.B.E. Department Of Landscape Architecture,U.T.M. Green Innovation Research Group, Evaluating the Impact of Vertical Greenery System on Cooling Effect on High Rise Buildings and Surroundings: A Review. Ruas. 9(2011) 1-9. 10.21776/ub.ruas. 2011.009.02.1

[24] K. Todo, D. Ogura, S. Hokoi,H. Kotani, Reduction of thermal impacts on indoor and outdoor environment by greening walls. Journal of Environmental Engineering (Transactions of AIJ). 73(2008) 1109-1116. https://doi.org/10.3130/ aije.73.1109

[25] Á. Takács, M. Kiss, Á. Gulyás, E. Tanács,N. Kántor, Solar Permeability of Different Tree Species in Szeged, Hungary. Geographica Pannonica. 20(2016) 32-41. https://doi.org/ $10.5937 / \mathrm{GeoPan} 1601032 \mathrm{~T}$

[26] T.E. Morakinyo, K.K. Lau, C. Ren, E. Ng, Performance of Hong Kong's common trees species for outdoor temperature regulation, thermal comfort, and energy saving. Build Environ. 137(2018) 157-170. 10.1016/j.buildenv.2018.04. 012

[27] A. Speak, L. Montagnani, C. Wellstein,S. Zerbe, The influence of tree traits on urban ground surface shade cooling. Landscape Urban Plan. 197(2020) 103748. ttps://doi.org/10.1016/j.landurbplan.2020. 103748

[28] K. Fabbri, G. Canuti,A. Ugolini, A methodology to evaluate outdoor microclimate of the archaeological site and vegetation role: A case study of the Roman Villa in Russi (Italy). Sustain. Cities Soc.. 35(2017) 107-133. 10.1016/j.scs.2017. 07.020

[29] M.A. Coombes, H.A. Viles,H. Zhang, Thermal blanketing by ivy (Hedera helix L.) can protect building stone from damaging frosts. Sci. Rep.-Uk. 8(2018) 9834. https://doi.org/10.1038/s41598018-28276-2

[30] T. Sternberg, H. Viles,A. Cathersides, Evaluating the role of ivy (Hedera helix) in moderating wall surface microclimates and contributing to the bioprotection of historic buildings. Build Environ. 46(2011) 293-297. https://doi.org/10.1016/j. buildenv.2010.07.017

[31] M.F. Andre, F. Vautier, O. Voldoire,E. Roussel, Accelerated stone deterioration induced by forest clearance around the Angkor temples. Sci Total Environ. 493(2014) 98-108. 10.1016/j.scitotenv. 2014.05.141

[32] W. Araoka, S. Hokoi, D. Ogura, C. Iba, Y. Li,S. $\mathrm{Hu}$, Deterioration and Preservation of City Wall in Nanjing. Energy Procedia. 132(2017) 945-950. https://doi.org/10.1016/j.egypro.2017.09.734

[33] Nanjing City Wall Protection and Management Centre, Inscription world Nanjing city wall brick (in Chinese). 2016, Nanjing: Nanjing Press.
958
[34] M. Matsumoto, Simultaneous Heat and Moisture Transfer and Moisture Accumulation in Building Materials. 1978, Kyoto University: Kyoto, Japan. [35] S. Frankenstein,G. Koenig, FASST Vegetation Models. 2004, U.S. Army Engineer Research and Development Center, Cold Regions Research and Engineering Laboratory (ERDC/CRREL).

[36] J.W. Deardorff, Efficient Prediction of Ground Surface Temperature and Moisture, With Inclusion of a Layer of Vegetation. Journal of Geophysical. C4(1978) $1889-1903$.

[37] J.A. Smith, K.J. Ranson, D. Nguyen, L. Balick, L.E. Link, L. Fritschen,B. Hutchison, Thermal vegetation canopy model studies. Remote Sens Environ. 11(1981) 311-326. https://doi.org/10.1016/0034-4257(81)90028-6

[38] L.K. Balick, R.K. Scoggins,L.E. Link, Inclusion of a Simple Vegetation Layer in Terrain Temperature Models for Thermal IR Signature Prediction. Ieee T. Geosci Remote. GE-19(1981) 143 - 152. https://doi.org/10.1109/TGRS.1981. 350343

[39] D.J. Sailor, A green roof model for building energy simulation programs. Energ Buildings. 40(2008) 1466-1478. https://doi.org/10.1016/j. enbuild.2008.02.001

[40] L. Malys, M. Musy,C. Inard, A hydrothermal model to assess the impact of green walls on urban microclimate and building energy consumption. Build Environ. 73(2014) 187-197. https://doi.org/ 10.1016/j.buildenv.2013.12.012

[41] Sumitada Kondou, Meteorology of the water environment - heat and moisture equilibrium on the ground surface (in Japanese). 1996: Asakura bookstore. 208-239.

[42] C. Hall,W.D. Hoff, Rising damp: capillary rise dynamics in walls. Proceedings of the Royal Society A. 463(2007) 1871 - 1884. https://doi.org/10.1098/rspa.2007.1855

[43] Y.J. Huang, H. Akbari, H. Taha,A.H. Rosenfeld, The Potential of Vegetation in Reducing Summer Cooling Loads in Residential Buildings. Journal Climate and Applied Meteorology. 26(1987) 11031116.

[44] J. Konarska, F. Lindberg, A. Larsson, S. Thorsson,B. Holmer, Transmissivity of solar radiation through crowns of single urban treesapplication for outdoor thermal comfort modelling. Theor Appl Climatol. 117(2014) 363-376. https://doi.org/10.1007/s00704-013-1000-3

[45] G.W. Scherer, Stress from crystallization of salt. Cement Concrete Res. 34(2004) 1613-1624. https://doi.org/10.1016/j.cemconres.2003.12.034

[46] R.J. Flatt, Salt damage in porous materials: how high supersaturations are generated. J. Cryst Growth. 242(2002) 435-454. https://doi.org/10.1016/S0022-0248(02)01429-X

[47] C. Rodriguez-Navarro,D. Eric, Salt Weathering: Influence of Evaporation Rate, Supersaturation and Crystallization Pattern. Earth Surf Proc Land. 
24(1999) 191 - 209. https://doi.org/10.1002/ (SICI) 1096-9837(199903) 24:33.0.CO;2-G

[48] L. Zhang, Q. Zhan,Y. Lan, Effects of the tree distribution and species on outdoor environment conditions in a hot summer and cold winter zone: A case study in Wuhan residential quarters. Build Environ. 130(2018) 27-39. https://doi.org/ 10.1016/j.buildenv.2017.12.014

[49] F. Kong, W. Yan, G. Zheng, H. Yin, G. Cavan, W.
Zhan, N. Zhang,L. Cheng, Retrieval of threedimensional tree canopy and shade using terrestrial laser scanning (TLS) data to analyze the cooling effect of vegetation. Agr Forest Meteorol. 217(2016) 22-34. https://doi.org/10.1016/j. agrformet.2015.11.005

[50] G. Caneva, G. Galotta, Cancellieri,V. Savo, Tree roots and damages in the Jewish catacombs of Villa Torlonia (Roma). J. Cult Herit,(2009) 53-62. 10.1016/j.culher.2008.04.005 